\title{
Oral HPV16 Prevalence in Oral Potentially Malignant Disorders and Oral Cavity Cancers
}

\author{
Kai Dun Tang ${ }^{1}$, Lilian Menezes ${ }^{1}$, Kurt Baeten ${ }^{2}$, Laurence J. Walsh ${ }^{3}{ }^{(D}$, Bernard C. S. Whitfield ${ }^{4}$, \\ Martin D. Batstone ${ }^{5}$, Liz Kenny ${ }^{6}$, Ian H. Frazer ${ }^{7}$, Gert C. Scheper ${ }^{8}$ and \\ Chamindie Punyadeera $1, *$ (D) \\ 1 Saliva \& Liquid Biopsy Translational Research Team, The School of Biomedical Sciences, Institute of Health \\ and Biomedical Innovation, Queensland University of Technology and the Translational Research Institute, \\ Queensland, Brisbane, QLD 4059, Australia; kai.tang@qut.edu.au (K.D.T.); applegate2k@yahoo.com (L.M.) \\ 2 Janssen Diagnostics, a division of Janssen Pharmaceutical NV, 2340 Beerse, Belgium; KBAETEN1@its.jnj.com \\ 3 School of Dentistry, The University of Queensland, Herston, QLD 4006, Australia; 1.walsh@uq.edu.au \\ 4 Logan Hospital Integrated Specialist ENT Service, Metro South Health Service District, Queensland Health, \\ Meadowbrook, QLD 4131, Australia; Bernard.Whitfield@health.qld.gov.au \\ 5 Department of Maxillo-Facial Surgery, Royal Brisbane and Women's Hospital, The University of Queensland, \\ Butterfield St, Herston, QLD 4029, Australia; Martin.Batstone@health.qld.gov.au \\ 6 Royal Brisbane and Women's Hospital, Central Integrated Regional Cancer Service, The University of \\ Queensland School of Medicine, Queenslands Health, Brisbane, QLD 4029, Australia; \\ lizkenny@bigpond.net.au \\ 7 Faculty of Medicine, The University of Queensland, Translational Research Institute, Brisbane, QLD 4102, \\ Australia; i.frazer@uq.edu.au \\ 8 Janssen Vaccines \& Prevention BV, 2333CN Leiden, The Netherlands; GSCHEPER@its.jnj.com \\ * Correspondence: chamindie.punyadeera@qut.edu.au; Tel.: +61-7-3138-0830
}

Received: 17 December 2019; Accepted: 30 January 2020; Published: 3 February 2020

\begin{abstract}
The role of human papillomavirus type 16 (HPV16) in oral potentially malignant disorders (OPMD) and oral cavity carcinoma (OC) is still under debate. We investigated HPV16 prevalence in unstimulated saliva, oral rinse samples, oral swabs and tumour biopsies collected from $\operatorname{OPMD}(n=83)$ and OC $(n=106)$ patients. HPV16 genotype, viral load, physical status (episomal vs. integrated) and tumour p16INK4a expression were determined. Oral HPV16 prevalence was higher in OC than in OPMD, but this difference was not statistically significant $(7.5 \%(8 / 106)$ versus $3.6 \%(3 / 83)$, odds ratio (OR): $2.18,95 \%$ confidence interval (CI): $0.56,8.48, p=0.26)$. There was a significant association $(p<0.05)$ between oral HPV16 infection and heavy tobacco consumption. Real-time PCR results indicated that no integration events occurred in either OPMD or OC cases based on the HPV16 E2/E6 ratio. HPV16 positive OPMD and OC patients had similar HPV16 E2 and E6 viral loads. The inter-rater agreement between tumour p16INK4a expression and oral HPV16 infection was considered as fair $(\mathrm{k}=0.361)$ for OC. Our data suggest that the involvement of HPV16 in oral carcinogenesis is limited.
\end{abstract}

Keywords: human papillomavirus; oral potentially malignant disorder; oral cavity cancer; saliva; viral load and HPV integration

\section{Introduction}

Oral cavity carcinoma (OC), which includes carcinomas of the mucosal part of the lip, is the most common subset of head and neck carcinomas (HNC), affecting approximately 300,000 patients annually worldwide [1]. Despite significant advances in cancer treatment, improvements in overall survival in OC have only been modest. [2,3]. Consistent with other malignant tumours, early detection 
has decreased treatment-associated morbidity and improved survival. More advanced malignancies, particularly those with nodal metastases, have much poorer prognoses, and require more invasive therapy. There is no universal, easy to use screening method for OC, in contrast to colorectal cancer (faecal occult blood) [4], or prostate cancer (prostate specific antigen) [5].

The widely accepted risk factors for carcinogenesis of OC are tobacco consumption use and alcohol consumption. Ample evidence suggests that the oral potentially malignant disorders (OPMD), which include leukoplakia, erythroplakia, oral lichen planus, oral submucous fibrosis, actinic cheilosis, and snuff patch, may also contribute to the development of OC [6]. In addition, human papillomavirus (HPV), an etiologic agent for cervical and oropharyngeal carcinoma (OPC) (which includes the tonsillar area, the base of tongue, the soft palate and the oropharynx), is a potential risk factor for OC. Over 200 types of HPV have been reported; however, only high-risk HPV types are associated with cancer development and progression. HPV16 is the most common high-risk HPV type, accounting for the majority of cases of cervical cancer and OPC [7,8].

Progression of precursor lesions of HPV associated to invasive carcinomas is closely related with integration of HPV DNA into the human genome [9]. Most clearly, HPV integration events are frequently detected in high-grade cervical intraepithelial neoplasia (CIN) [10]. HPV integration usually results in the deregulation of the E2 opening reading frame (ORF), leading to reduced E2 expression and upregulation of expression of the viral E6 and E7 oncogenes which can abrogate the cell cycle checkpoint and induce genomic instability [11]. However, any role of HPV integration in OC remains to be elucidated. It is well established that p16INK4a (cyclin-dependent kinase 2a) immunohistochemical (IHC) staining can only be a surrogate biomarker of HPV for OPC patients, not for other HNC patients [12]. Accumulating evidence suggests that the importance of additional HPV testing in HPV-associated cancer diagnosis and prognosis [13]. Previous studies have demonstrated that the presence of HPV DNA in tumour tissues is significantly correlated with HPV DNA positivity in saliva samples collected from OPC patients, thus suggesting the use of salivary HPV as a biomarker for the detection of HPV DNA in OPC patients [14,15].

While HPV plays a significant role in OPC, to date it is unclear to what extent this also applies to OC. The first aim of this study was to determine the HPV16 prevalence in OPMD and OC using different sampling methods (unstimulated saliva, oral rinse, oral swab and tumour biopsies). The second aim was to investigate any associations between oral HPV16 infection and lifestyle risk factors (i.e., smoking and drinking) in OPMD and OC. The final aim was to investigate whether the integration of HPV DNA into the human genome was a critical factor in oral carcinogenesis.

\section{Materials and Methods}

\subsection{Study Design}

This study was approved by institutional ethics committees from the University of Queensland [HREC No: 2014000679 and 2014000862], Queensland University of Technology [HREC No: 1400000617 and 1400000641], the Princess Alexandra Hospital [HREC Number: HREC/12/QPAH/381] and the Royal Brisbane and Women's Hospital [HREC/16/QRBW/447]. A total of 204 patients who had been diagnosed with OPMD $(n=86)$ or OC $(n=118)$ were recruited from the Royal Brisbane and Women's Hospital, Logan Hospital, Princess Alexandra Hospital, University of Queensland Dental School clinics, and private dental practices (Figure 1). The p16INK4a status in patients with OC lesion was evaluated by Queensland pathologists using CINtec ${ }^{\circledR}$ p16INK4a Histology Kit (E6H4 clone) (Roche MTM Laboratories, Heidelberg, Germany). p16INK4a was considered positive when there was a strong, diffuse nuclear and cytoplasmic staining pattern in the majority $(>70 \%)$ of tumour cells. The clinical stages of OC patients were classified according to the American Joint Committee on Cancer (AJCC, version 8) based on Tumour-Nodal-Metastasis (TNM). All participants gave written informed consent prior to sampling. 


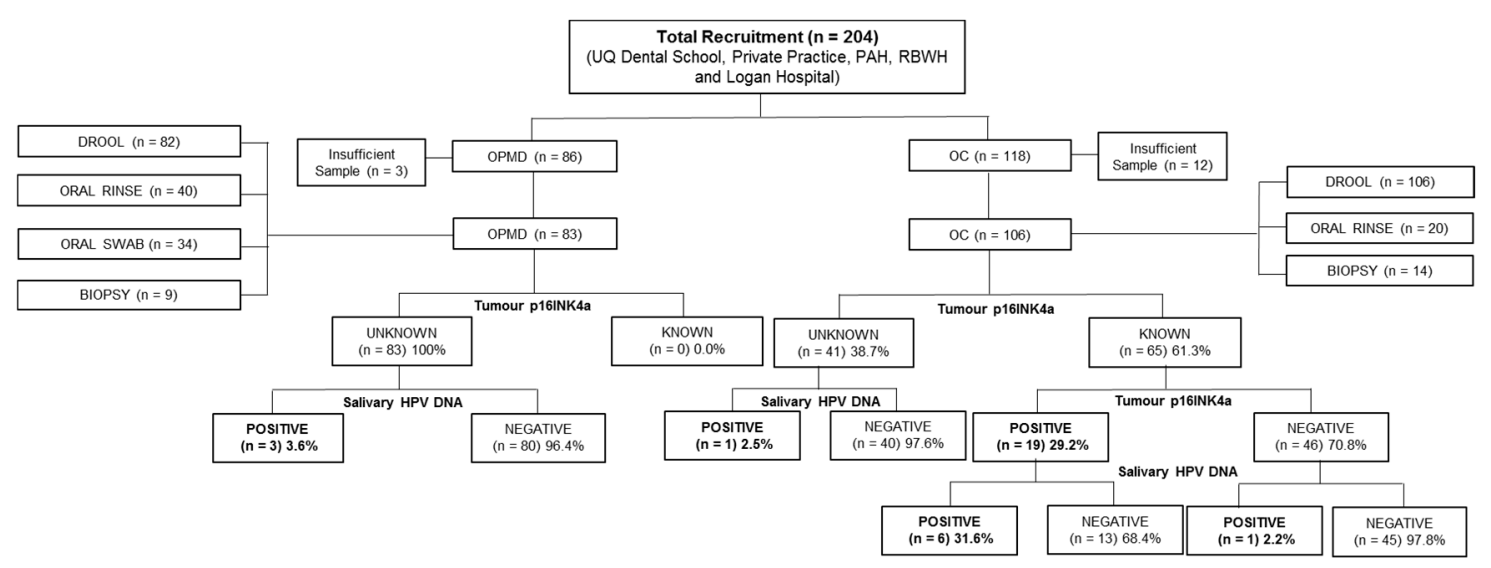

Figure 1. Flow chart of study recruitment.

\subsection{Collection of Unstimulated Saliva, Oral Rinse, Oral Swab and Tissue Samples}

The number and type of samples that were obtained are depicted in Figure 1. Unstimulated saliva samples were collected from patients with OPMD $(n=85)$ and OC $(n=118)$, as described in our previous studies $[16,17]$. Briefly, participants were asked to pool saliva in the mouth $(2-5 \mathrm{~min})$ before drooling into a Falcon tube.

Oral rinse samples were collected from patients with OPMD $(n=40)$ and OC $(n=20)$, using methods employed previously. Briefly, participants were asked to swish and gargle for 1-2 min with $2 \times 10 \mathrm{~mL}$ $0.9 \%$ saline.

Oral swab samples were collected from patients with OPMD $(n=34)$. Participants were asked to rake along the inside of their buccal mucosa with a DNA.SAL collection device (Oasis Diagnostics ${ }^{\circledR}$, Vancouver, WA, USA) for 30-60 s.

Tumour biopsies were obtained from patients with OPMD $(n=9)$ and OC $(n=14)$ after surgical resection. All samples were frozen immediately upon collection and transported back to the laboratory for subsequent processing.

\subsection{DNA Isolation}

Total DNA was extracted from the unstimulated saliva, oral rinse samples, oral swab samples and tumour biopsies using the QIAmp DNA Mini Kit (Qiagen, Germantown, MD, USA) as per the manufacturer's protocol. Briefly, $200 \mu \mathrm{L}$ volumes of lysis buffer was added to the cell pellets with proteinase $\mathrm{K}$ and incubated at $56^{\circ} \mathrm{C}$ for $10 \mathrm{~min}$. For tumour biopsies, $200 \mu \mathrm{L}$ of tissue lysis buffer was added with Proteinase $\mathrm{K}$ and incubated at $56^{\circ} \mathrm{C}$ until the pellets were completely lysed. Then, $200 \mu \mathrm{L}$ lysis buffer was added to the mixture and incubated at $70^{\circ} \mathrm{C}$ for $10 \mathrm{~min}$. After lysis, $200 \mu \mathrm{L}$ volumes of $100 \%$ ethanol was added to the mixture, which was then transferred to QIAmp DNA mini spin columns, following the manufacturer's instructions.

\subsection{Low and High-Risk HPV DNA Genotyping}

To investigate the HPV type distribution in patients with OPMD and OC, a high-throughput MALDI-TOF mass spectrometry-based method (Mass Array Platform, Agena Bioscience, Hamburg, Germany) was used, as previously described [18]. This method is able to detect 16 HPV DNA types (HPV16, 18, 31, 33, 35, 39, 45, 51, 52, 53, 56, 58, 59, 66, 68 and 73) in a single well.

\subsection{HPV16 DNA Nested PCR}

For a sensitive and specific HPV16 PCR, two pairs of primers that flank the region of HPV16 E6 opening reading frame (ORF) were designed. Diluted DNA samples (70 ng) were added to the first PCR master mix containing 10× PCR buffer, $50 \mathrm{mM} \mathrm{MgCl2}, 10 \mathrm{mM}$ dNTP (No dTTP), $10 \mathrm{mM}$ dUTP, $10 \mu \mathrm{M}$ HPV16 1F (GTTTCAGGACCCACAGGAGC), 10 MM HPV16 1R (GTCATATACCTCACGTCGCAGT), 
Uracil DNA Glycosylase (UDG) and Platinum Taq DNA polymerase (Thermo Fisher Scientific, Waltham, MA, USA) in a total volume of $10 \mu \mathrm{L}$. The first PCR used the following conditions: $50^{\circ} \mathrm{C}$ for $10 \mathrm{~min}$, $95{ }^{\circ} \mathrm{C}$ for $10 \mathrm{~min}$; 25 cycles at $95{ }^{\circ} \mathrm{C}$ for $30 \mathrm{sec}, 60^{\circ} \mathrm{C}$ for $30 \mathrm{sec}$ and $72{ }^{\circ} \mathrm{C}$ for $30 \mathrm{sec}$. Next, $2 \mu \mathrm{L}$ of the first PCR product was used as the template for the second PCR, with $10 \mu \mathrm{M}$ HPV16 $2 \mathrm{~F}$ (CAGGAGCGACCCAGAAAGTT) and $10 \mu \mathrm{M}$ HPV16 2R (ACTGTTGCTTGCAGTACACAC), and in the absence of UDG. The second PCR conditions were as follows: $95^{\circ} \mathrm{C}$ for $2 \mathrm{~min} ; 30$ cycles at $95^{\circ} \mathrm{C}$ for $30 \mathrm{sec}, 65^{\circ} \mathrm{C}$ for $30 \mathrm{sec}$ and $72{ }^{\circ} \mathrm{C}$ for $30 \mathrm{sec}$; and a final extension at $72{ }^{\circ} \mathrm{C}$ for $5 \mathrm{~min}$. Human $\beta$-globin (Forward: CAACTTCCACGGTTCACC; Reverse: GAAGAGCCAAGGACAGGTAC) was used as an internal control. The second PCR products were subjected to gel electrophoresis. Gel images were recorded using the ChemiDoc ${ }^{\mathrm{TM}}$ Gel Imaging System (Bio-rad, Hercules, CA, USA). HPV16 positivity was further confirmed by using Sanger sequencing of the PCR products.

\subsection{HPV16 E2 and E6/7 DNA qPCR Analysis}

Diluted DNA samples (50 ng) were used in duplicate in qPCR. The qPCR assay was carried out with the QuantStudio ${ }^{\mathrm{TM}} 7$ Flex Real-Time PCR System (Applied Biosystems, Foster City, CA, USA). Forward and reverse primers targeted against the region of HPV16 E2 (Forward: AACGAAGTATCCTCTCCTGAAATTATTAG; Reverse: CCAAGGCGACGGCTTTG) and E6/7 (Forward: ACCGGTCGATGTATGTCTTGTTG; Reverse: GATCAGTTGTCTCTGGTTGCAAATC) OFR were used. Human $\beta$-globin was used as an internal control. HPV16 E2 and E6 DNA standard calibration curves were generated by using qPCR, respectively, by plotting threshold cycle (Ct values) against the logarithm of the copy number of eightfold serially diluted $(1 \times 108$ to $1 \times 101$ copies $)$ of pHPV-16 plasmid DNA (American Type Culture Collection (ATCC) ${ }^{\circledR} 45113^{\mathrm{TM}}$ ). Each of the eight-point dilutions were given the same amount of total DNA by spiking with HPV16 negative HNC cell line DNA (SCC-9). Samples were classified as HPV positive when a Ct value for either E2 or E6 was obtained, and as HPV negative when both E2 and E6 Ct values were undetermined: these were assigned a value of 40 .

\subsection{Physical Status of HPV16}

The HPV16 physical status in HPV16 positive OPMD and OC patients $(n=11)$ was classified based on the ratio of E2 and E6/7 copy numbers, as described previously [19-21]. HPV16 was regarded as a purely episomal form when the ratio of $\mathrm{E} 2$ and $\mathrm{E} 6 / 7$ was equal to or more than 1, in a mixed form with an increased E6/7 copy number (ratio $<1$ ), and in a purely integrated form when E2 was absent.

\subsection{Statistical Analysis}

Fisher's exact test was used to measure the significance of differences in age, race, sex, drinking and smoking status and oral HPV16 infection between OPMD and OC patients, and between HPV16 negative and positive cases. The odds ratio (OR) with $95 \%$ confidence interval $(\mathrm{CI})$ was calculated and used to estimate the relationship between HPV16 status and OC. The non-parametric Mann-Whitney U test was used to compare the differences in HPV16 viral load between OPMD and OC. The Cohen's kappa coefficient with $95 \%$ CI was used to measure the inter-rater agreement between salivary HPV16 DNA testing and p16INK4a expression (https://www.graphpad.com/quickcalcs/kappa1.cfm). The sensitivity, specificity, positive predictive values (PPV), negative predictive values (NPV) and their $95 \%$ confidence intervals were calculated. All statistical tests were two-sided, and p-values less than 0.05 were considered significant. Statistical analyses were performed using GraphPad Prism 7 software version 7 (GraphPad Software Inc., La Jolla, CA, USA). 


\section{Result}

\subsection{Patient Characteristics}

The details of patients with OPMD $(n=83)$ and OC $(n=106)$ who could provide a sufficient amount of DNA are summarized in Table 1, Supplementary Tables S1 and S2. Most OPMD and OC patients were of Caucasian ethnicity and aged 55 years or above. OC cases were more prevalent in males ( $p=0.01)$, ever-smokers (current and former smokers) $(p=0.03)$ and ever-drinkers (standard drink $>7$ per week) ( $p=0.003)$ when compared to OPMD cases. Detection of HPV16 was rare in both OC and OPMD, and while it was more common in OC than OPMD $[n=8(7.5 \%)$ versus $n=3(3.6 \%)$, OR 2.18, 95\% CI 0.56-8.48, $p=0.26$ ], this did not reach statistical significance. HPV16 in saliva fractions (unstimulated saliva/oral rinse) correlated positively with the detection of HPV DNA in tumour biopsies of patients with OPMD and OC $(n=23)$ (Supplementary Tables S3 and S4).

Table 1. Patient Demographics.

\begin{tabular}{|c|c|c|c|c|c|c|}
\hline \multirow{2}{*}{ Variables } & \multirow{2}{*}{ Categories } & \multicolumn{2}{|c|}{ OC $(N=106)$} & \multicolumn{2}{|c|}{ OPMD $(\mathrm{N}=83)$} & \multirow{2}{*}{$p$-Value } \\
\hline & & No. & $\%$ & No. & $\%$ & \\
\hline \multirow{2}{*}{ Age (years) } & $\leq 55$ & 17 & 16.0 & 20 & 24.1 & 0.2 \\
\hline & $>55$ & 89 & 84.0 & 63 & 75.9 & \\
\hline \multirow{2}{*}{ Sex } & Male & 75 & 70.8 & 43 & 51.8 & 0.01 \\
\hline & Female & 31 & 29.2 & 40 & 48.2 & \\
\hline \multirow{3}{*}{ Smoking Status } & Ever & 83 & 78.3 & 52 & 62.7 & 0.03 \\
\hline & Never & 23 & 21.7 & 30 & 36.1 & \\
\hline & Unknown & 0 & 0.0 & 1 & 1.2 & \\
\hline \multirow{3}{*}{ Drinking Status } & Ever & 49 & 46.2 & 19 & 22.9 & 0.003 \\
\hline & Never & 55 & 51.9 & 57 & 68.7 & \\
\hline & Unknown & 2 & 1.9 & 7 & 8.4 & \\
\hline \multirow{2}{*}{ HPV16 Infection } & Yes & 8 & 7.5 & 3 & 3.6 & 0.35 \\
\hline & No & 98 & 92.5 & 80 & 96.4 & \\
\hline
\end{tabular}

\subsection{Characteristics of HPV16-Positive Patients with Oral Lesions}

Patient clinical and epidemiological characteristics in relation to oral HPV16 infection are detailed in Table 2. There were no significant differences in age, sex and drinking status between the HPV16-negative and -positive groups. All 11 HPV16-positive patients with oral lesions (OC and OPMD) were ever-smokers, compared with 70\% (124/177) of HPV16-negative patients $(p=0.036)$.

Table 2. Differences between HPV16 negative and HPV16 positive patients with oral lesions.

\begin{tabular}{ccccccc}
\hline \multirow{2}{*}{ Variables } & \multirow{2}{*}{ Categories } & \multicolumn{2}{c}{ HPV16 Negative } & \multicolumn{2}{c}{ HPV16 Positive } & $p$-Value \\
\cline { 3 - 7 } & & No. & $\mathbf{\%}$ & No. & $\mathbf{\%}$ & \\
\hline \multirow{2}{*}{ Age (years) } & $\leq 55$ & 35 & 19.7 & 2 & 18.2 & $>1.000$ \\
& $>55$ & 143 & 80.3 & 9 & 81.8 & \\
\hline \multirow{2}{*}{ Sex } & Male & 109 & 61.2 & 9 & 81.8 & 0.214 \\
& Female & 69 & 38.8 & 2 & 18.2 & \\
\hline \multirow{2}{*}{ Smoking Status } & Ever & 124 & 70.1 & 11 & 100.0 & 0.036 \\
& Never & 53 & 29.9 & 0 & 0.0 & \\
\hline \multirow{2}{*}{ Drinking Status } & Ever & 62 & 36.7 & 6 & 54.5 & 0.336 \\
& Never & 107 & 63.3 & 5 & 45.5 & \\
\hline
\end{tabular}




\subsection{HPV16 DNA Physical Status and Viral Loads in OPMD and OC}

A purely episomal form of HPV16 with the E2/E6 ratio equal to or more than 1 was detected in all 11 HPV16-positive OPMD and OC cases, as summarized in Table 3. HPV16-positive OPMD and OC cases had similar HPV16 E2 and E6/7 viral loads, as shown in Figure 2.

Table 3. Salivary HPV16 viral load and viral physical status in oral potentially malignant disorder (OPMD) and oral cavity carcinoma (OC) patients.

\begin{tabular}{cccccccc}
\hline OC & Genotype & E2 CT & $\begin{array}{c}\text { E2 Viral Copies } \\
\text { per 50 ng }\end{array}$ & E6 CT & $\begin{array}{c}\text { E6 Viral Copies } \\
\text { per 50 ng }\end{array}$ & $\begin{array}{c}\text { E2/E6 } \\
\text { Ratio }\end{array}$ & $\begin{array}{c}\text { Physical } \\
\text { Status }\end{array}$ \\
\hline OC 2 & 16 & 22.07 & 7882.79 & 21.52 & 5114.37 & 1.54 & Episomal \\
OC 46 & 16 & 27.71 & 180.35 & 27.39 & 103.83 & 1.74 & Episomal \\
OC 49 & 16 & 20.90 & $17,245.15$ & 19.69 & $17,296.29$ & 1.00 & Episomal \\
OC 51 & 16 & 30.92 & 21.03 & 31.34 & 7.56 & 2.78 & Episomal \\
OC 54 & 16 & 30.90 & 21.24 & 30.21 & 15.97 & 1.33 & Episomal \\
OC 70 & 16 & 29.40 & 58.02 & 28.30 & 56.77 & 1.02 & Episomal \\
OC 84 & 16 & 23.45 & 3124.61 & 22.97 & 1963.43 & 1.59 & Episomal \\
OC 94 & 16 & 28.95 & 78.37 & 29.51 & 25.40 & 3.09 & Episomal \\
OPMD 6 & 16 & 22.21 & 7188.51 & 21.36 & 5709.28 & 1.26 & Episomal \\
OPMD 11 & 16 & 25.50 & 790.81 & 25.40 & 390.00 & 2.03 & Episomal \\
OPMD 30 & 16 & 26.68 & 358.78 & 26.31 & 213.20 & 1.68 & Episomal \\
\hline
\end{tabular}
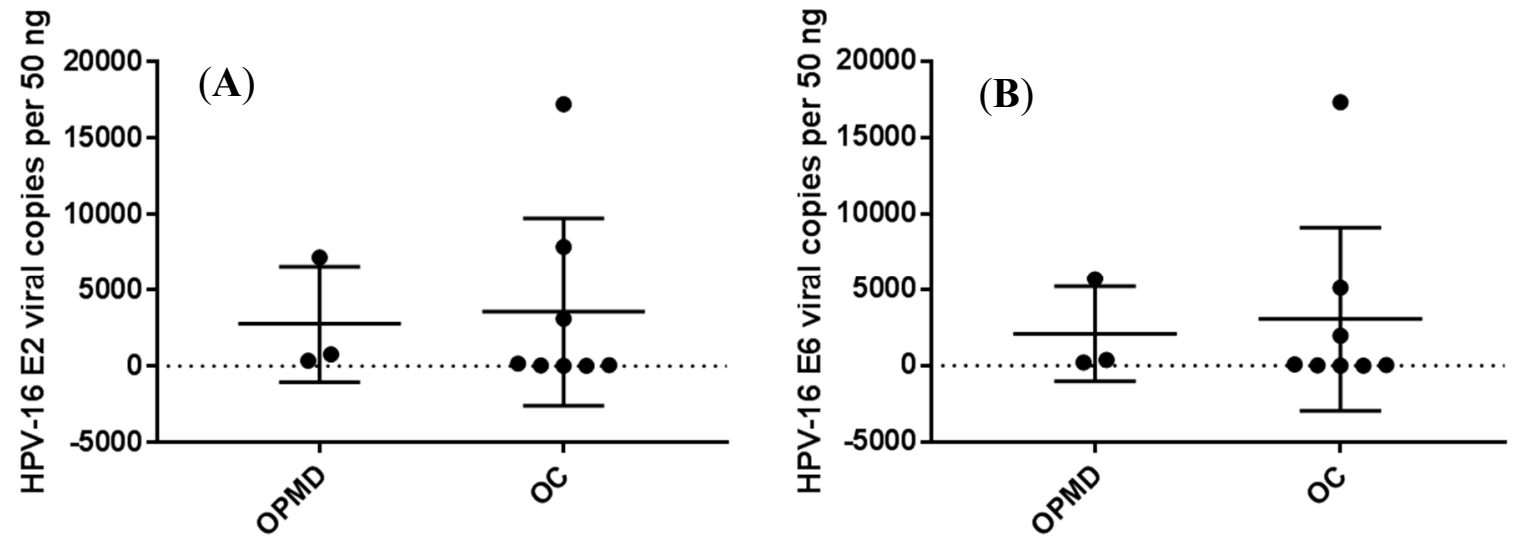

Figure 2. Salivary HPV16 E2 (A) and E6 (B) viral copies in OPMD and OC patients.

\subsection{Tumour p16INK4a Expression and Oral HPV16 Infection in OC}

65 (61\%) OC biopsies were examined by p16INK4a IHC analysis. A total of 19 out of $65(29 \%)$ OC biopsies were positive for p16INK4a staining, while $46(71 \%)$ were negative. Among the 19 p16INK4a-positive OC cases, 6 (32\%) were positive for HPV16 DNA. On the other hand, 1 of the $46(2 \%)$ p16INK4a-negative OC cases was positive for HPV16 DNA. The inter-rater agreement between tumour p16INK4a expression and oral HPV16 infection was considered as fair $(\mathrm{k}=0.36195 \% \mathrm{CI}$ $[0.121 ; 0.601])$ for OC, as shown in Table 4.

Table 4. Oral HPV16 infection and tumour p16INK4a in OC patients.

\begin{tabular}{ccc}
\hline \multirow{2}{*}{ Salivary HPV16 DNA Status } & \multicolumn{2}{c}{ p16INK4a Status } \\
\cline { 2 - 3 } & Positive & Negative \\
\hline Positive & $6(31.6 \%)$ & $1(2.2 \%)$ \\
Negative & $13(68.4 \%)$ & $45(97.8 \%)$ \\
\hline
\end{tabular}

Sensitivity $0.32(0.15,0.54)$, Specificity $0.98(0.89,1.00)$, Positive Predictive Value (PPV) $0.86(0.49,1.00)$, Negative Predictive Value (NPV) $0.78(0.65,0.86)$. 


\section{Discussion}

$\mathrm{HPV}$ is the most common sexually transmitted infection, causing an estimated 630,000 (4.5\%) new cancer cases globally $[1,22]$. Growing evidence supports the concept that oncogenic type HPV16 is responsible for most cases of cervical cancer and OPC $[23,24]$. The role of HPV in the development of cancers in other regions of the mouth is still unclear. To our knowledge, this study is the largest Australian population-based cohort investigation into the possible relationship between oral HPV infection and the risk of OC. Our results show non-significantly higher HPV16 prevalence in OC than in OPMD. In addition, HPV16 positivity was significantly associated with heavy tobacco consumption. Intriguingly, only the purely episomal HPV16 form was detected in all HPV16 positive OPMD and OC cases. No appreciable difference in viral load was found between HPV16 positive OPMD and OC cases. Together, these data suggest that HPV is unlikely to play an etiological role in oral carcinogenesis.

The reported HPV prevalence in both OPMD and OC varies from $0 \%$ to $100 \%[25,26]$. This extreme variation may be explained by several factors, including different ethnicity and variations in sampling methods, as well as in the techniques used for the detection of HPV [27,28]. For Australia, there is no published literature on HPV prevalence rates in OPMD. We found a relatively low prevalence of HPV in OPMD patients when compared to the majority of previous studies $[29,30]$. However, similar findings have been shown in a recent Hungarian study, which reported a low level of HPV DNA positivity in saliva samples from OPMD patients. Nevertheless, our reported HPV prevalence rate in OC patients is concordant with the findings of previous studies from other western countries [31-33] including a recent Australian study by Emmett et al. [34]. More importantly, our results also corroborate the findings of previous investigations in other countries, including Hungary [35], Iran [36], Kazakhstan [37], Romania [38], South Korea [39] and Thailand [40]. However, there was no statistically significant difference in HPV prevalence between OPMD and OC in this Australian cohort.

We found no statistically significant association between oral HPV16 infection and socio-demographic parameters, except for tobacco consumption. Heavy tobacco consumption has been found to facilitate HPV viral persistence, which may contribute to the malignant transformation of cervical cancer [41,42]. However, the current literature on the association between heavy tobacco consumption and HPV-positive HNC is not well delineated [43-45]. Several studies suggest that there is an additive or synergistic interaction between heavy tobacco consumption and an elevated risk of developing persistent oral HPV infection and HPV-associated HNC [46,47]. Similar findings are observed in our current study, showing that heavy tobacco consumption is strongly associated with HPV16-positive patient with OPMD and OC lesions.

High-risk HPV DNA integration into the human cellular genome, followed by the upregulation of E6 and E7, often trigger malignant transformation of cells in cervical and anal cancer as well as in OPC $[48,49]$. Our previous work indicated that most HPV16 OPC cases showed evidence of integration (either partially or fully) in both saliva and tumour fractions $[15,50]$. However, little attention to date has been paid to investigate whether HPV integration is a necessary step in the carcinogenesis of OC. Our real-time PCR results showed no integration events in both OPMD and OC, according to the HPV16 E2/E6 ratio. Similar findings of low HPV integration rates have been reported in OC patients when compared to OPC patients [49,51]. This is further supported by previous reports of no statistically significant differences in prognostic and survival outcomes between HPV-negative and -positive patients with non-OPC conditions, including OC [52-54]. Indeed, a recent study demonstrated that HPV is uncommonly associated with the oncogenesis of OC [55]. Furthermore, both HPV16-positive OPMD and OC had similar viral loads. Thus, the potential etiologic role of HPV in oral carcinogenesis seems rather modest.

Based on decades of accumulated evidence, accurate HPV testing is crucial for clinical decision making and treatment planning in HNC patients [56]. The current 'gold standard' of p16INK4a staining that is used for the detection of HPV in patients with non-OPC and OPMD has been shown to have several drawbacks [57-59]. A large multicentre study reported a discordance between p16INK4a expression and HPV infection in patients with non-oropharyngeal HNC $(n=683)$, including subsites 
of the oral cavity, hypopharynx, and larynx [58]. This is further supported by a recent study by Zafereo et al. [60] which indicated that only six of the 40 p16INK4a-positive OC cases had detectable HPV DNA, whilst 31 of the 110 p16INK4a-negative OC cases were HPV DNA positive. This suggests that the overexpression of p16INK4a is not a reliable surrogate marker of HPV in OC. Similar findings of low concordance were made in the current study. The underlying mechanism of p16INK4a overexpression in OC may not be driven solely by HPV infection. If this is indeed the case, using p16INK4a as a standalone marker for the detection of HPV in OC would not be recommended.

The major limitations of the present study are the relatively small sample sizes, the limited availability of fresh tumour samples of OPMD and OC cases, and the use of saliva for HPV testing which might not reflect the HPV positivity in both OPMD and OC samples. Furthermore, additional studies will be needed to confirm whether our findings apply to all regions in Australia. In this study, p16INK4a IHC analysis was only performed in OC tumour samples with features suspicious of HPV infection. Finally, an additional robust method is needed for future studies of HPV integration events.

\section{Conclusions}

In conclusion, we found a low oral HPV16 prevalence in both OPMD and OC. Interestingly, we observed a statistically significant association between oral HPV16 infection and heavy tobacco consumption. However, no integration events occurred in both OPMD and OC cases that were examined. Taken together, our results do not support a major role of HPV in oral carcinogenesis.

Supplementary Materials: The following are available online at http://www.mdpi.com/2218-273X/10/2/223/s1. Table S1: Clinical characteristics of OPMD. Table S2: Clinical characteristics of OC. Table S3: HPV-16 genotyping in unstimulated saliva, oral rinse, oral swab and tumour biopsies of OPMD patients. Table S4: HPV-16 infection (saliva and tumour biopsy) and tumour p16INK4a in OC patients.

Author Contributions: Conceptualization, K.D.T., K.B., I.H.F., G.C.S. and C.P.; methodology, validation, formal analysis and investigation, K.D.T. and C.P.; data curation, K.D.T., L.M., L.J.W., B.C.S.W., M.D.B. and L.K.; writing — original draft preparation, K.D.T.; writing—review and editing, all authors; funding acquisition, C.P. All authors have read and agreed to the published version of the manuscript.

Funding: This work was supported by the Queensland Centre for Head and Neck funded by Atlantic Philanthropies, the Queensland Government and the Janssen: Pharmaceutical Companies of Johnson \& Johnson. CP is supported by QUT VC Fellowship.

Acknowledgments: We would like to thank Trang Le, Jennifer Edmunds, Charmaine Micklewright, Jacqui Keller and Dana Middleton and the staff at the RBWH and PAH and for their assistance in the recruitment of study patients and collection of clinical samples. We also thank Darryl Irwin (Agena Bioscience, Australia), for kindly providing assistance with the detection of low and high-risk HPV genotyping in the patient with OPMD and OC lesions. We also would like to acknowledge Paul Slowey (CEO of Oasis Diagnostics, USA) for providing the DNA.SAL scrapers.

Conflicts of Interest: The authors declare no conflict of interest.

\section{References}

1. Ferlay, J.; Soerjomataram, I.; Dikshit, R.; Eser, S.; Mathers, C.; Rebelo, M.; Parkin, D.M.; Forman, D.; Bray, F. Cancer incidence and mortality worldwide: Sources, methods and major patterns in globocan 2012. Int. J. Cancer 2015, 136, E359-E386. [CrossRef] [PubMed]

2. Argiris, A.; Brockstein, B.E.; Haraf, D.J.; Stenson, K.M.; Mittal, B.B.; Kies, M.S.; Rosen, F.R.; Jovanovic, B.; Vokes, E.E. Competing causes of death and second primary tumors in patients with locoregionally advanced head and neck cancer treated with chemoradiotherapy. Clin. Cancer Res. 2004, 10, 1956-1962. [CrossRef] [PubMed]

3. Jemal, A.; Siegel, R.; Ward, E.; Hao, Y.; Xu, J.; Murray, T.; Thun, M.J. Cancer statistics, 2008. CA Cancer J. Clin. 2008, 58, 71-96. [CrossRef] [PubMed]

4. Medical Advisory Secretariat. Fecal occult blood test for colorectal cancer screening: An evidence-based analysis. Ont Health Technol Assess. Ser. 2009, 9, 1-40.

5. Brawer, M.K. Prostate-specific antigen: Current status. CA Cancer J. Clin. 1999, 49, 264-281. [CrossRef] 
6. Warnakulasuriya, S.; Johnson, N.W.; van der Waal, I. Nomenclature and classification of potentially malignant disorders of the oral mucosa. J. Oral Pathol. Med. 2007, 36, 575-580. [CrossRef]

7. Crosbie, E.J.; Einstein, M.H.; Franceschi, S.; Kitchener, H.C. Human papillomavirus and cervical cancer. Lancet 2013, 382, 889-899. [CrossRef]

8. Elrefaey, S.; Massaro, M.A.; Chiocca, S.; Chiesa, F.; Ansarin, M. Hpv in oropharyngeal cancer: The basics to know in clinical practice. Acta Otorhinolaryngol. Ital. 2014, 34, 299-309.

9. Snijders, P.J.; Steenbergen, R.D.; Heideman, D.A.; Meijer, C.J. Hpv-mediated cervical carcinogenesis: Concepts and clinical implications. J. Pathol. 2006, 208, 152-164. [CrossRef]

10. Wentzensen, N.; Vinokurova, S.; von Knebel Doeberitz, M. Systematic review of genomic integration sites of human papillomavirus genomes in epithelial dysplasia and invasive cancer of the female lower genital tract. Cancer Res. 2004, 64, 3878-3884. [CrossRef]

11. Longworth, M.S.; Laimins, L.A. Pathogenesis of human papillomaviruses in differentiating epithelia. Microbiol. Mol. Biol. Rev. 2004, 68, 362-372. [CrossRef] [PubMed]

12. El-Naggar, A.K.; Westra, W.H. P16 expression as a surrogate marker for hpv-related oropharyngeal carcinoma: A guide for interpretative relevance and consistency. Head Neck 2012, 34, 459-461. [CrossRef] [PubMed]

13. Nauta, I.H.; Rietbergen, M.M.; van Bokhoven, A.; Bloemena, E.; Lissenberg-Witte, B.I.; Heideman, D.A.M.; Baatenburg de Jong, R.J.; Brakenhoff, R.H.; Leemans, C.R. Evaluation of the eighth tnm classification on p16-positive oropharyngeal squamous cell carcinomas in the netherlands and the importance of additional hpv DNA testing. Ann. Oncol. 2018, 29, 1273-1279. [CrossRef] [PubMed]

14. Qureishi, A.; Ali, M.; Fraser, L.; Shah, K.A.; Moller, H.; Winter, S. Saliva testing for human papilloma virus in oropharyngeal squamous cell carcinoma: A diagnostic accuracy study. Clin. Otolaryngol. 2018, 43, 151-157. [CrossRef]

15. Tang, K.D.; Baeten, K.; Kenny, L.; Frazer, I.H.; Scheper, G.; Punyadeera, C. Unlocking the potential of saliva-based test to detect hpv-16-driven oropharyngeal cancer. Cancers 2019, 11, 473. [CrossRef] [PubMed]

16. Sun, C.X.; Bennett, N.; Tran, P.; Tang, K.D.; Lim, Y.; Frazer, I.; Samaranayake, L.; Punyadeera, C. A pilot study into the association between oral health status and human papillomavirus-16 infection. Diagnostics 2017, 7, 11. [CrossRef] [PubMed]

17. Tang, K.D.; Kenny, L.; Perry, C.; Frazer, I.; Punyadeera, C. The overexpression of salivary cytokeratins as potential diagnostic biomarkers in head and neck squamous cell carcinomas. Oncotarget 2017, 8, 72272-72280. [CrossRef]

18. Carolis, S.; Pellegrini, A.; Santini, D.; Ceccarelli, C.; De Leo, A.; Alessandrini, F.; Arienti, C.; Pignatta, S.; Tesei, A.; Mantovani, V.; et al. Liquid biopsy in the diagnosis of hpv DNA in breast lesions. Future Microbiol. 2018, 13, 187-194. [CrossRef]

19. Khanal, S.; Shumway, B.S.; Zahin, M.; Redman, R.A.; Strickley, J.D.; Trainor, P.J.; Rai, S.N.; Ghim, S.J.; Jenson, A.B.; Joh, J. Viral DNA integration and methylation of human papillomavirus type 16 in high-grade oral epithelial dysplasia and head and neck squamous cell carcinoma. Oncotarget 2018, 9, 30419-30433. [CrossRef]

20. Li, S.; Shen, H.; Li, J.; Hou, X.; Zhang, K.; Li, J. Prevalence of the integration status for human papillomavirus 16 in esophageal carcinoma samples. Turk. J. Gastroenterol. 2018, 29, 157-163. [CrossRef]

21. Peitsaro, P.; Johansson, B.; Syrjanen, S. Integrated human papillomavirus type 16 is frequently found in cervical cancer precursors as demonstrated by a novel quantitative real-time pcr technique. J. Clin. Microbiol. 2002, 40, 886-891. [CrossRef] [PubMed]

22. De Martel, C.; Plummer, M.; Vignat, J.; Franceschi, S. Worldwide burden of cancer attributable to HPV by site, country and hpv type. Int. J. Cancer 2017, 141, 664-670. [CrossRef] [PubMed]

23. Haghshenas, M.; Golini-Moghaddam, T.; Rafiei, A.; Emadeian, O.; Shykhpour, A.; Ashrafi, G.H. Prevalence and type distribution of high-risk human papillomavirus in patients with cervical cancer: A population-based study. Infect. Agent Cancer 2013, 8, 20. [CrossRef] [PubMed]

24. Berman, T.A.; Schiller, J.T. Human papillomavirus in cervical cancer and oropharyngeal cancer: One cause, two diseases. Cancer 2017, 123, 2219-2229. [CrossRef]

25. Gupta, S.; Gupta, S. Role of human papillomavirus in oral squamous cell carcinoma and oral potentially malignant disorders: A review of the literature. Indian J. Dent. 2015, 6, 91-98. [CrossRef] 
26. Syrjanen, S.; Lodi, G.; von Bultzingslowen, I.; Aliko, A.; Arduino, P.; Campisi, G.; Challacombe, S.; Ficarra, G.; Flaitz, C.; Zhou, H.M.; et al. Human papillomaviruses in oral carcinoma and oral potentially malignant disorders: A systematic review. Oral Dis. 2011, 17 (Suppl. 1), 58-72. [CrossRef]

27. Feller, L.; Wood, N.H.; Khammissa, R.A.; Lemmer, J. Human papillomavirus-mediated carcinogenesis and HPV-associated oral and oropharyngeal squamous cell carcinoma. Part 1: Human papillomavirus-mediated carcinogenesis. Head Face Med. 2010, 6, 14. [CrossRef]

28. Kreimer, A.R.; Clifford, G.M.; Boyle, P.; Franceschi, S. Human papillomavirus types in head and neck squamous cell carcinomas worldwide: A systematic review. Cancer Epidemiol. Biomark. Prev. 2005, 14, 467-475. [CrossRef]

29. Feller, L.; Lemmer, J. Oral leukoplakia as it relates to hpv infection: A review. Int. J. Dent. 2012, $2012,540561$. [CrossRef]

30. Ferreira, L.L.; Biasoli, E.R.; Bernabe, D.G.; Nunes, C.M.; Miyahara, G.I. Plasma HPV DNA is detectable in oral leukoplakia patients. Pathol. Res. Pract. 2017, 213, 759-765. [CrossRef]

31. Lingen, M.W.; Xiao, W.; Schmitt, A.; Jiang, B.; Pickard, R.; Kreinbrink, P.; Perez-Ordonez, B.; Jordan, R.C.; Gillison, M.L. Low etiologic fraction for high-risk human papillomavirus in oral cavity squamous cell carcinomas. Oral Oncol. 2013, 49, 1-8. [CrossRef] [PubMed]

32. Smith, E.M.; Rubenstein, L.M.; Haugen, T.H.; Pawlita, M.; Turek, L.P. Complex etiology underlies risk and survival in head and neck cancer human papillomavirus, tobacco, and alcohol: A case for multifactor disease. J. Oncol. 2012, 2012, 571862. [CrossRef] [PubMed]

33. Termine, N.; Giovannelli, L.; Rodolico, V.; Matranga, D.; Pannone, G.; Campisi, G. Biopsy vs. Brushing: Comparison of two sampling methods for the detection of hpv-DNA in squamous cell carcinoma of the oral cavity. Oral Oncol. 2012, 48, 870-875. [CrossRef] [PubMed]

34. Emmett, S.; Jenkins, G.; Boros, S.; Whiteman, D.C.; Panizza, B.; Antonsson, A. Low prevalence of human papillomavirus in oral cavity squamous cell carcinoma in Queensland, Australia. ANZ J. Surg. 2017, 87, 714-719. [CrossRef]

35. Hettmann, A.; Demcsak, A.; Bach, A.; Decsi, G.; Dencs, A.; Palinko, D.; Rovo, L.; Terhes, G.; Urban, E.; Buzas, K.; et al. Prevalence and genotypes of human papillomavirus in saliva and tumor samples of head and neck cancer patients in Hungary. Infect. Genet. Evol. 2018, 59, 99-106. [CrossRef]

36. Akhondnezhad, M.; Haghshenas, M.R.; Ghasemi, M.; Mousavi, T. The prevalence and genotyping of human papillomavirus in patients with oral tumors in health centers and clinics of Mazandaran in Iran. Virusdisease 2018, 29, 297-302. [CrossRef]

37. Adilbay, D.; Adilbayev, G.; Kidirbayeva, G.; Shipilova, V.; Sadyk, Z.; Koyanbekova, G.; Sokolenko, E.; Klozar, J. HPV infection and p16 expression in oral and oropharyngeal cancer in Kazakhstan. Infect. Agent Cancer 2018, 13, 2. [CrossRef]

38. Ursu, R.G.; Danciu, M.; Spiridon, I.A.; Ridder, R.; Rehm, S.; Maffini, F.; McKay-Chopin, S.; Carreira, C.; Lucas, E.; Costan, V.V.; et al. Role of mucosal high-risk human papillomavirus types in head and neck cancers in Romania. PLoS ONE 2018, 13, e0199663. [CrossRef]

39. Kim, S.M.; Kwon, I.J.; Myoung, H.; Lee, J.H.; Lee, S.K. Identification of human papillomavirus (HPV) subtype in oral cancer patients through microarray technology. Eur. Arch. Otorhinolaryngol. 2018, 275, 535-543. [CrossRef]

40. Chotipanich, A.; Siriarechakul, S.; Mungkung, O.O. Role of high-risk human papillomavirus in the etiology of oral and oropharyngeal cancers in Thailand: A case-control study. SAGE Open Med. 2018, 6. [CrossRef]

41. Ho, G.Y.; Kadish, A.S.; Burk, R.D.; Basu, J.; Palan, P.R.; Mikhail, M.; Romney, S.L. HPV 16 and cigarette smoking as risk factors for high-grade cervical intra-epithelial neoplasia. Int. J. Cancer 1998, 78, 281-285. [CrossRef]

42. Castle, P.E.; Wacholder, S.; Lorincz, A.T.; Scott, D.R.; Sherman, M.E.; Glass, A.G.; Rush, B.B.; Schussler, J.E.; Schiffman, M. A prospective study of high-grade cervical neoplasia risk among human papillomavirus-infected women. J. Natl. Cancer Inst. 2002, 94, 1406-1414. [CrossRef] [PubMed]

43. Sinha, P.; Logan, H.L.; Mendenhall, W.M. Human papillomavirus, smoking, and head and neck cancer. Am. J. Otolaryngol 2012, 33, 130-136. [CrossRef]

44. Mirghani, H.; Leroy, C.; Chekourry, Y.; Casiraghi, O.; Auperin, A.; Tao, Y.; Nguyen, F.; Caroline, E.; Breuskin, I.; Plana, A.M.; et al. Smoking impact on hpv driven head and neck cancer's oncological outcomes? Oral Oncol. 2018, 82, 131-137. [CrossRef] 
45. Applebaum, K.M.; Furniss, C.S.; Zeka, A.; Posner, M.R.; Smith, J.F.; Bryan, J.; Eisen, E.A.; Peters, E.S.; McClean, M.D.; Kelsey, K.T. Lack of association of alcohol and tobacco with hpv16-associated head and neck cancer. J. Natl. Cancer Inst. 2007, 99, 1801-1810. [CrossRef]

46. Smith, E.M.; Ritchie, J.M.; Summersgill, K.F.; Hoffman, H.T.; Wang, D.H.; Haugen, T.H.; Turek, L.P. Human papillomavirus in oral exfoliated cells and risk of head and neck cancer. J. Natl. Cancer Inst. 2004, 96, 449-455. [CrossRef]

47. Smith, E.M.; Rubenstein, L.M.; Haugen, T.H.; Hamsikova, E.; Turek, L.P. Tobacco and alcohol use increases the risk of both HPV-associated and HPV-independent head and neck cancers. Cancer Causes Control. 2010, 21, 1369-1378. [CrossRef]

48. Parfenov, M.; Pedamallu, C.S.; Gehlenborg, N.; Freeman, S.S.; Danilova, L.; Bristow, C.A.; Lee, S.; Hadjipanayis, A.G.; Ivanova, E.V.; Wilkerson, M.D.; et al. Characterization of HPV and host genome interactions in primary head and neck cancers. Proc. Natl. Acad. Sci. USA 2014, 111, 15544-15549. [CrossRef]

49. Kim, S.H.; Koo, B.S.; Kang, S.; Park, K.; Kim, H.; Lee, K.R.; Lee, M.J.; Kim, J.M.; Choi, E.C.; Cho, N.H. HPV integration begins in the tonsillar crypt and leads to the alteration of p16, EGFR and c-MYC during tumor formation. Int. J. Cancer 2007, 120, 1418-1425. [CrossRef]

50. Tang, K.D.; Kenny, L.; Frazer, I.H.; Punyadeera, C. High-risk human papillomavirus detection in oropharyngeal cancers: Comparison of saliva sampling methods. Head Neck 2019, 41, 1484-1489. [CrossRef]

51. Lee, S.Y.; Cho, N.H.; Choi, E.C.; Baek, S.J.; Kim, W.S.; Shin, D.H.; Kim, S.H. Relevance of human papilloma virus (HPV) infection to carcinogenesis of oral tongue cancer. Int. J. Oral Maxillofac. Surg. 2010, 39, 678-683. [CrossRef] [PubMed]

52. Li, H.; Park, H.S.; Osborn, H.A.; Judson, B.L. Sex differences in patients with high risk HPV-associated and hpv negative oropharyngeal and oral cavity squamous cell carcinomas. Cancers Head Neck 2018, 3, 4. [CrossRef] [PubMed]

53. Fakhry, C.; Westra, W.H.; Wang, S.J.; van Zante, A.; Zhang, Y.; Rettig, E.; Yin, L.X.; Ryan, W.R.; Ha, P.K.; Wentz, A.; et al. The prognostic role of sex, race, and human papillomavirus in oropharyngeal and nonoropharyngeal head and neck squamous cell cancer. Cancer 2017, 123, 1566-1575. [CrossRef] [PubMed]

54. Lassen, P.; Primdahl, H.; Johansen, J.; Kristensen, C.A.; Andersen, E.; Andersen, L.J.; Evensen, J.F.; Eriksen, J.G.; Overgaard, J.; Danish, H.; et al. Impact of HPV-associated p16-expression on radiotherapy outcome in advanced oropharynx and non-oropharynx cancer. Radiother Oncol. 2014, 113, 310-316. [CrossRef] [PubMed]

55. Zammit, A.P.; Sinha, R.; Cooper, C.L.; Perry, C.F.L.; Frazer, I.H.; Tuong, Z.K. Examining the contribution of smoking and HPV towards the etiology of oral cavity squamous cell carcinoma using high-throughput sequencing: A prospective observational study. PLoS ONE 2018, 13, e0205406. [CrossRef] [PubMed]

56. Chu, A.; Genden, E.; Posner, M.; Sikora, A. A patient-centered approach to counseling patients with head and neck cancer undergoing human papillomavirus testing: A clinician's guide. Oncologist 2013, 18, 180-189. [CrossRef]

57. Wasylyk, B.; Abecassis, J.; Jung, A.C. Identification of clinically relevant HPV-related HNSCC: In p16 should we trust? Oral Oncol. 2013, 49, e33-e37. [CrossRef]

58. Chung, C.H.; Zhang, Q.; Kong, C.S.; Harris, J.; Fertig, E.J.; Harari, P.M.; Wang, D.; Redmond, K.P.; Shenouda, G.; Trotti, A.; et al. P16 protein expression and human papillomavirus status as prognostic biomarkers of nonoropharyngeal head and neck squamous cell carcinoma. J. Clin. Oncol. 2014, 32, 3930-3938. [CrossRef]

59. Montebugnoli, L.; Gissi, D.B.; Scapoli, L.; Palmieri, A.; Morandi, L.; Manelli, I.; Foschini, M.P. P16(ink4) expression is not associated with human papillomavirus in oral lichen planus. Oral Surg. Oral Med. Oral Pathol. Oral Radiol. 2014, 118, 694-702. [CrossRef]

60. Zafereo, M.E.; Xu, L.; Dahlstrom, K.R.; Viamonte, C.A.; El-Naggar, A.K.; Wei, Q.; Li, G.; Sturgis, E.M. Squamous cell carcinoma of the oral cavity often overexpresses $\mathrm{p} 16$ but is rarely driven by human papillomavirus. Oral Oncol. 2016, 56, 47-53. [CrossRef]

(C) 2020 by the authors. Licensee MDPI, Basel, Switzerland. This article is an open access article distributed under the terms and conditions of the Creative Commons Attribution (CC BY) license (http://creativecommons.org/licenses/by/4.0/). 